\title{
Acompanhamento terapêutico: consideraçōes sobre uma clínica a céu aberto
}

\author{
Therapeutic accompaniment: considerations about \\ an open-air clinic
}

\author{
Júlia Roberta de Oliveira Carvalho Caetano (orcid.org/0000-0001-6780-4570)' \\ Antônio Márcio Ribeiro Teixeira (orcid.org/0000-0003-3867-2681)²
}

\begin{abstract}
Resumo
O presente estudo pretende abordar o Acompanhamento Terapêutico (AT) e sua prática a partir do viés da psicanálise, o qual questionamos enquanto método para o AT. Discorreremos sobre a história da loucura, compreendendo quais posições o louco ocupou na sociedade e ressaltando o papel do discurso científico em seu tratamento. Veremos como a Reforma Psiquiátrica possibilitou a liberdade do tratamento, bem como o surgimento do AT. Considerando a especificidade do AT no encontro com o contingente, analisaremos o conceito aristotélico da prudência, que se articula com a contingência, visto que discursamos acerca de uma clínica em movimento que se depara com variáveis não controláveis. A prudência nos dirá de um saber que se manifesta a partir da contingência, logo, pensaremos nessa lógica a serviço de um método que se constrói na colocação em ato. Concluímos ressaltando a função política do AT de sempre reforçar o cuidado em liberdade.
\end{abstract}

Palavras-chave: Acompanhamento terapêutico. Psicanálise. Reforma psiquiátrica. Prudência.

\begin{abstract}
The present study intends to approach Therapeutic Accompaniment (TA) and its practice from the perspective of psychoanalysis, which we question as a method for TA. We will discuss the history of madness, understanding what positions the madman occupied in society and emphasizing the role of scientific discourse in his treatment. We will see how the Psychiatric Reform enabled the freedom of treatment, as well as the emergence of TA. Considering the specificity of TA in the encounter with the contingent, we will analyze the Aristotelian concept of prudence, which is articulated with contingency, since we discuss about a moving clinic that is faced with uncontrollable variables. Prudence will tell us of a knowledge that manifests itself from contingency, so we will think of this logic at the service of a method that is built in putting into action. We conclude by emphasizing the political function of the TA, of always reinforce care in freedom.
\end{abstract}

\footnotetext{
${ }^{1}$ Universidade Federal de Minas Gerais, Belo Horizonte, Brasil. E-mail: juliaroc@msn.com.

2 Universidade Federal de Minas Gerais, Belo Horizonte, Brasil. E-mail: amrteixeira@uol.com.br.
} 
Keywords: Therapeutic accompaniment. Psychoanalysis. Psychiatric reform. Prudence.

Em 1605, Miguel de Cervantes trouxe ao mundo as aventuras de Dom Quixote e Sancho Pança, o fidalgo e seu fiel escudeiro. Enquanto o Cavaleiro da Triste Figura empunhava sua espada contra os moinhos de vento, seu companheiro não deixava de acompanhá-lo. Seria essa uma primeira experiência do Acompanhamento Terapêutico ${ }^{3}$ Em que pese a alusão a Sancho Pança, só a companhia a um fidalgo cavaleiro será suficiente? Será que não corremos o risco de esquecer o termo "terapêutico", apagando-o da relação entre acompanhante e acompanhado, ocupando assim um lugar comum? Somente a companhia pelos mais diversos trajetos não caracteriza um AT, pois, para que seu trabalho se efetive, é preciso que haja uma intenção terapêutica. Destacamos que não se trata de um lugar comum, ou de uma posição assistencialista, pois a aposta é justamente nessa clínica em movimento que opera num lugar de fronteira: entre o paciente e a instituição, a família, a cidade, ou seja, entre o paciente e o laço social. Acompanhar o paciente em seu cotidiano implica consequências clínicas, políticas e sociais, bem como uma disposição ética para ocupar esse lugar.

A prática do AT é de grande relevância nos casos em que o paciente necessita ser acompanhado em sua reinserção na sociedade, em tarefas como pegar ônibus, ir a bancos, consultas, circular na cidade. Por ter vários usos e atividades, trata-se de uma prática sujeita às contingências dos espaços onde se circula, por onde faz-se circular o louco e sua palavra. Nesse sentido, Palombini (2006), ao falar da cidade como espaço da loucura e consequentemente da ação do acompanhante terapêutico, alerta:

E seu exercício [do acompanhante terapêutico] - que se dá entre lugares, entre o serviço e a rua, entre o quarto e a sala, fora de lugar, a céu aberto - presentifica uma exigência que a reforma psiquiátrica vem colocar aos seus profissionais, seja qual for o dispositivo em causa: o fato de que uma clínica a serviço dos processos de

\footnotetext{
3 Para melhor conduzir o trabalho, optamos por adotar a sigla AT para designar o Acompanhamento Terapêutico, remetendo à prática/dispositivo.
} 
desinstitucionalização coloca em jogo a desinstitucionalização da clínica mesma. (p. 117, grifo nosso)

Enfatizamos essa questão justamente por suscitar o debate da clínica, mas sobretudo da herança que temos da psiquiatria clássica, em que o modo de tratamento foi marcado pela segregação. Conforme veremos mais adiante, se a ciência se caracteriza como um discurso que autoriza o abandono, com o AT há a possibilidade de acompanhar quem foi abandonado: através de sua presença e de sua escuta, o acompanhante terapêutico poderá ouvir esse sujeito, reconhecendo-o em sua singularidade.

O intuito deste artigo é abordar essa clínica em movimento a partir de sua concepção no contexto da Reforma Psiquiátrica. Considerando o viés psicanalítico, questionamos acerca de um método para o AT, no intuito de promover o sujeito acompanhado como operador. Para isso, discorreremos brevemente sobre a história da loucura para situar as posições que o louco ocupou e ressaltar o papel da Reforma Psiquiátrica no tratamento de saúde mental e no surgimento do AT, destacando a dimensão da reabilitação psicossocial. Considerando a especificidade do AT no encontro com o contingente, analisaremos o conceito aristotélico da prudência, que se articula com a contingência, visto que abordamos uma clínica a céu aberto que se depara com diversas variáveis não controláveis. A prudência nos remeterá a um saber que se manifesta a partir da contingência, onde poderemos pensar nessa lógica a serviço de um método que se constrói na colocação em ato.

\section{Loucura e ciência: qual tratamento para o louco?}

Foucault (1978) nos indica que na Antiguidade não se tinha a necessidade de segregar os loucos, sendo que a loucura passou por diversas expressões culturais e circulou socialmente de maneira livre antes que fosse redirecionada ao confinamento. $\mathrm{Na}$ Renascença, o louco possui uma vida errante, e segundo nos pontuam Laia e Aguiar (2017), nos séculos XV e XVI temos uma loucura considerada como oracular, contendo um "saber enigmático" (p. 13).

O saber próprio da loucura se conecta com a razão, conforme indica Foucault (1978): ambas "entram numa relação eternamente reversível que faz com que toda loucura tenha 
sua razão que a julga e controla, e toda razão sua loucura na qual ela encontra sua verdade irrisória" (p. 35). Nesse momento histórico, o louco é admitido em um estado livre, circula e carrega consigo o saber enigmático.

Para Foucault (1978), o pensamento de Descartes é central para a subversão da loucura, pois a coloca no lado oposto da razão. Assim, a partir do século XVII, a loucura estará relacionada ao erro, à impossibilidade do pensamento. Segundo Teixeira (2016), "para que a loucura ganhasse seu lugar perceptivo próprio, foi necessário um gesto que a desenredasse violentamente do pensamento" (p. 332), o que acarretará na destituição da loucura enquanto experiência de lucidez. Com essa subversão, inicia-se o período das internações.

No século XVII, são criadas as casas de internamento; mais precisamente, é no ano de 1656 que o Hospital Geral é fundado em Paris. Porém, mesmo com os grandes locais de internamento nesse período, ainda não temos um saber científico sobre a loucura, ou mesmo um tratamento médico: o que se tem é algo da ordem da moral. Nesse sentido, o hospital geral é um verdadeiro depósito não só de loucos como também de doentes, velhos, blasfemadores, miseráveis em suas existências de modo geral.

Ao final do século XVIII, temos o papel fundamental do capitalismo, que promove uma classificação entre quem poderia trabalhar e quem não poderia, resgatando os internos ditos "válidos" dos locais de internação (Foucault, 1978). O que ocorre então é que "os loucos - impossibilitados de trabalhar e vistos como perigosos - acabaram por restar como derradeiros remanescentes do Grande Enclausuramento" (Laia \& Aguiar, 2017, p. 18). Temos então o nascimento do manicômio e, consequentemente, da psiquiatria, a partir de Pinel, em 1793 (Foucault, 1978). Com esse fato, é possível traçar um delineamento de cunho mais científico da loucura, com influências positivistas. O que se observa também é a transformação dos hospitais psiquiátricos: se antes eram de cunho assistencial, a partir de Pinel, temos uma constituição da instituição hospitalar, de método clínico e investigativo.

O panorama da psiquiatria, que envolve diversos atores tais como Clérambault, Esquirol, Kraepelin, Jaspers, dentre outros, será constituído a partir daí enquanto implicação do tratamento mental articulado à ciência e ao seu discurso. Destacamos, então, um ponto importante da imbricação entre prática científica e prática de segregação: 
[...] ao definir alguém como "alienado", o discurso segregacionista apoia-se na autoridade científica para silenciar sua fala, seja excluindo-o fisicamente da comunidade, através de medidas de internação sistemática, seja tratando cientificamente sua diferença nos termos veladamente morais de comportamento inadaptado ou de déficit cognitivo. (Teixeira, 2016, p. 334)

Assim, a introdução da ciência no tratamento da loucura nos indica o silenciamento do sujeito tido como louco, e vemos então de que maneira a ciência se caracteriza como um discurso que autoriza o abandono. O discurso da ciência, ao constituir-se a partir do cogito cartesiano, isenta-se da verdade, pois sabemos que o que está em jogo é o saber. No caso da loucura, é justamente esse saber produzido pelo discurso científico que permite tal segregação, apoiado na exclusão que é feita a partir do que Descartes coloca enquanto condição para o ser ou o existir: o pensar. Se o louco não pensa, consequentemente não pode estar incluído no sistema regido pela ciência. Essa característica é que nos revela o cerne do tratamento da loucura a partir de então, pois "seja qual for o seu nível de êxito ou dificuldade em tratar cientificamente o fenômeno mental, a ciência estabelece axiomaticamente, em sua fundação, que da loucura, como pensamento, nada se deve esperar, ela nada tem a dizer" (Teixeira, 2016, p. 334). Ela nada tem a dizer e é apenas um erro a ser corrigido, a partir dos padrões científicos de controle.

O tratamento da loucura no modelo hospitalocêntrico ${ }^{4}$ possui a característica de uma experiência controlada. Conforme nos recorda Teixeira (2011), dentro do hospital temos o controle das variáveis, ou mesmo sua eliminação, inclusive tendo diversos protocolos aplicáveis ao controle do sono, alimentação, medicação, horários e tarefas a serem realizadas.

Essas características do modelo hospitalocêntrico se encaixam no conceito de instituição total, conforme ressalta Erving Goffman (1974) em Manicômios, prisões e conventos. Uma das características mais marcantes desse processo de institucionalização é a mortificação do eu, visto que há "uma série de rebaixamentos, degradações, humilhações e profanações do eu" (Goffman, 1974, p. 24). A mortificação do eu é composta por processos padronizados, tais como a barreira entre o internado e o mundo externo e os ritos de

\footnotetext{
4 Tratamento centrado na internação hospitalar.
} 
admissão. Ao ser admitido, o internado é despojado de seus bens e pertences, que são substituídos por roupas e itens padronizados. Diante disso que é imposto, retomamos o discurso da ciência que declara que a loucura é apenas um erro a ser corrigido, devendo se encaixar no padrão ou naquilo que é padronizado na instituição psiquiátrica. Isso inclui a eliminação das variáveis subjetivas, que fogem ao que é considerado padrão.

A experiência hospitalar da loucura, com seus protocolos e controle de variáveis, remete-nos a um "universo da precisão", termo inserido pelo filósofo Alexandre Koyré (1991) em seu texto “Do mundo do 'mais-ou-menos' ao universo da precisão". Nesse texto, o autor apresenta a mudança do mundo do mais ou menos ao mundo da precisão, no que se refere à história da ciência. Enquanto a precisão estará ligada aos instrumentos de medida e à exatidão por eles proposta, o mais ou menos se refere à vida cotidiana, que é caracterizada justamente pelo seu caráter móvel (Koyré, 1991).

Retomando a comparação do universo da precisão ao hospital psiquiátrico, os instrumentos de precisão dos quais nos fala Koyré também estão presentes na tentativa de exatidão no tratamento da loucura. Não podemos deixar de lembrar dos instrumentos realizados nas lobotomias, os aparelhos de eletrochoque, ou mesmo de pensar o próprio hospital psiquiátrico como um instrumento de controle da loucura. Um mundo da precisão que descarta a subjetividade - e ainda hoje contamos com certos aparatos que se prestam a isso, tais como os exames de neuroimagem e o desenvolvimento de manuais de transtornos mentais. Seria um déjà-vu?

\section{Reforma psiquiátrica, reabilitação psicossocial e psicanálise}

O panorama do tratamento da loucura permanece o mesmo até o período que sucede à Segunda Guerra Mundial, quando se iniciam projetos de Reforma Psiquiátrica pela Europa e Estados Unidos. A partir disso, em alguns países, tem-se a modificação na forma do tratamento psiquiátrico e a consequente abertura do espaço antimanicomial. Esses projetos incluem a comunidade terapêutica, a psicoterapia institucional, a psiquiatria de setor, a psiquiatria preventiva, a antipsiquiatria e a psiquiatria democrática italiana (Amarante, 1995). 
Cada um desses projetos se diferencia em suas especificidades, sendo voltados ou para a reforma do espaço asilar, ou para atividades externas ao hospital. Conforme nos elucida Amarante (1995), a comunidade terapêutica inglesa (que tem como expoentes Maxwell Jones, Sullivan, Bion, Reichman, dentre outros) e a psicoterapia institucional francesa (representada por Jean Oury) se ocupam da reformulação institucional, mas pontua que Jean Oury traz uma proposta que preza a abertura de novas possibilidades terapêuticas, tais como a inclusão de ateliês. Já a psiquiatria de setor e a psiquiatria preventiva possuem um trabalho mais voltado para a comunidade: o objetivo era a obsolescência dos hospitais psiquiátricos. Porém, a antipsiquiatria, com ideias dos psiquiatras ingleses Laing e Cooper, traz uma crítica bem pontual acerca do valor que se dava ao saber médico, numa proposta de horizontalidade das relações dentro da instituição.

Entretanto, segundo Amarante (1995), todos esses projetos seriam "reformas da reforma", pois considera que é somente a partir da intervenção de Franco Basaglia e da psiquiatria democrática italiana que se desconstrói o paradigma psiquiátrico clássico, com um projeto de desinstitucionalização. Com Basaglia, temos a desconstrução do espaço manicomial, através de suas experiências em Gorizia e, particularmente, em Trieste, onde são construídos novos centros de atendimento em saúde mental fora do hospital psiquiátrico.

No Brasil, a reforma psiquiátrica terá início nos anos finais da década de 1970, com um importante papel do Movimento dos Trabalhadores em Saúde Mental (MTSM). Segundo Amarante (1995), o MTSM é o responsável pela vinda de Franco Basaglia ao Brasil em 1979, o que impulsiona o movimento em nosso país, quando surgem denúncias das condições dos hospitais psiquiátricos brasileiros.

Ao final da década de 1980, ocorre a I Conferência Nacional de Saúde Mental, e é criado o primeiro Centro de Atenção Psicossocial (CAPS), em São Paulo. Além disso, há a criação do projeto de Lei $n^{\circ} 3.657 / 89$ pelo deputado federal Paulo Delgado - aprovado como lei em 2001, sob o número 10.216. Essa lei assegura os direitos e a proteção dos sujeitos com sofrimento mental, configurando a redução dos leitos em hospitais psiquiátricos, bem como a regulação das internações, a serem indicadas quando os recursos em meio aberto não forem suficientes. O que se preconiza com a lei é o tratamento de saúde 
mental em ambiente aberto e visando a reinserção social, a partir da reabilitação psicossocial.

Portanto, a partir da reforma psiquiátrica, um novo tema é inserido na saúde mental: a reabilitação psicossocial. Logicamente, com a mudança do tratamento da loucura, evidencia-se um novo modo de tratamento em meio aberto. Mas mesmo o termo reabilitação psicossocial requer cuidados e merece ser detalhado. Guerra (2004) nos apresenta um panorama detalhado desse termo a partir da realidade brasileira após a reforma. Torna-se claro que ainda há uma multiplicidade de modos de operar a partir do conceito da reabilitação, que são explicitados no livro organizado por Ana Pitta (2016), Reabilitação psicossocial no Brasil. A autora explica que a reabilitação psicossocial "está associada a um sem-número de iniciativas mais ou menos articuladas que buscam reduzir o poder cronificador e desabilitante dos tradicionais tratamentos, desenvolvendo-se dentro e fora dos hospitais e se utilizando de um sem-número de técnicas" (Pitta, 2016, p. 28).

Para além da própria multiplicidade que o termo evoca, Guerra (2004) salienta as controvérsias em torno da questão, que enfocam justamente um questionamento da psicose e sua ruptura e de como a reabilitação psicossocial atuaria aí: "como voltar a ser o que se era antes, se é exatamente isso que se perde no desencadeamento psicótico?" (p. 90). Diante disso, a autora nos apresenta três modelos epistêmicos que norteiam a reabilitação psicossocial: 1) modelos psicoeducativos; 2) modelos sociopolíticos ou críticos e; 3) modelos de orientação clínica.

O primeiro modelo se presta à adequação do sujeito, através da aprendizagem de habilidades. O segundo modelo leva em conta as variáveis sociais e políticas das realidades locais de onde se realiza a reabilitação, preconizando as redes de intervenção e a capacidade contratual dos sujeitos. Já o terceiro modelo se caracteriza por uma crítica aos modelos psicoeducativos e uma aproximação dos modelos sociopolíticos, justamente por considerar que "há uma dimensão particular, única e irredutível de inscrição do sujeito na linguagem e na cultura" (Guerra, 2004, p. 91). Esse modelo de orientação clínica nos remete justamente ao papel da psicanálise dentro da reforma psiquiátrica e da reabilitação psicossocial. Contudo, ressaltamos que outros modelos clínicos baseados em abordagens diferentes também atuaram e ainda atuam na reforma psiquiátrica. 
Conforme já abordamos anteriormente, a ciência dá um passo na transposição do mundo do mais ou menos em direção ao universo da precisão - e inclusive foi possível situar a experiência hospitalocêntrica da loucura nesse universo da precisão. Mas estamos lidando com a doença mental: como é possível permanecer no procedimento controlado em sua abordagem, considerando que a partir da reforma psiquiátrica o tratamento é oferecido em meio aberto, em serviços substitutivos, apresentando a todo momento variáveis não controláveis? De fato, Teixeira (2011) pontua que com essa substituição do modelo hospitalar pelo tratamento em meio aberto, a experimentação controlada da loucura dá lugar a "uma experiência do atendimento cuja orientação somente pode ser concebida no momento mesmo em que essa experiência se apresenta" (p. 4). Podemos dizer que essa experiência será marcada pelo encontro com o contingente. A inserção no espaço da cidade abre novas possibilidades, e consequentemente não se pode escapar da ocorrência de imprevistos, que convocam um modo diferente de situar o modelo de atendimento em saúde mental.

Mas cabe ressaltar uma questão instigante, visto que, décadas após o início da reforma psiquiátrica e dessa revolução no tratamento da loucura, ainda temos características de sua experimentação controlada: o uso desenfreado dos medicamentos psiquiátricos, a incidência do Manual Diagnóstico e Estatístico de Transtornos Mentais (DSM) com papel preponderante de diagnosticar e classificar, os exames de neuroimagem que atestam o crescimento das neurociências, e até mesmo através dos sistemas de registro de informações no âmbito do Sistema Único de Saúde (SUS), como o Registro das Ações Ambulatoriais de Saúde (RAAS) que solicita o Código Internacional de Doenças (CID) dos usuários.

Diante dessa atualização do apagamento do sujeito através de sistemas de classificações e diagnósticos, e considerando a forma de tratamento proclamada pela reforma psiquiátrica, torna-se importante ressaltar o papel da psicanálise na apropriação desse espaço. A psicanálise vai na contramão daquilo que reiteradamente tolhe a palavra do sujeito em meio às classificações. É necessário sempre retomar o caminho escolhido por Freud, que "no lugar de pensar o sofrimento na perspectiva objetivante do saber científico, que silencia a palavra do louco, preferiu ouvir o que seu paciente tinha a dizer" (Teixeira, 
2016, p. 340). E é a partir dessa recomendação que podemos localizar a relação fundamental da psicanálise com a saúde mental, dando ouvidos àqueles que sofrem e têm o que dizer.

Explicitamos anteriormente que existem diferentes modos de reabilitação psicossocial associados à reforma psiquiátrica, e já situamos bem o lugar da psicanálise em reconhecer o que há de particular em cada sujeito. Isso porque temos em Saraceno (2001) uma crítica da reabilitação que responde a uma lógica de controle e, consequentemente, a uma lógica de contenção - ações que descartam o sujeito e seu saber. Essa crítica realizada por Saraceno (2001) nos leva a concordar com Teixeira (2010), que ao diferenciar inclusão social de inserção aponta que a primeira estaria ligada à lógica de controle através de um saber terapêutico vindo do Estado ou de outro poder. O assistencialismo, que muitas vezes ocorre dentro da saúde mental, responde à essa lógica, em prol dos direitos que foram historicamente negados aos pacientes ao longo de uma prática manicomial. Algo da ordem da reparação, que se torna imprescindível. Sabemos que os direitos dos loucos foram negados, mas chamamos a atenção para essa atualização do controle social através do saber que se julga ter sobre os sujeitos, amparado na necessidade de assistência.

Mas, diferente da inclusão social, a inserção seria um termo

[...] que passa a significar, a nossos olhos, um vínculo absolutamente distinto desse modo de relação ao Outro $^{5}$ calcado nos mecanismos de submissão ao poder. Sua visada implica antes, por essência, uma relação definida pelos meios possíveis de negociação do sujeito com o Outro, em cujo saldo se manifesta não apenas uma transformação do modo anterior de vínculo, como também uma modificação essencial tanto da parte do sujeito quanto da parte do Outro com o qual esse sujeito vem compor. (Teixeira, 2010, p. 3)

\footnotetext{
5 O conceito de Outro foi formulado por Lacan. A mudança que ele propõe da palavra outro em minúsculo para a palavra Outro em maiúsculo é justamente para se desvencilhar do outro como próximo, como semelhante. O Outro constitui assim uma alteridade enquanto campo. No Seminário 3, Lacan (1955-1956/1985a) nos diz que o Outro está exclú́do na fala delirante; portanto, o Outro enquanto organizador da estrutura Simbólica não se efetiva no caso das psicoses, fazendo com que o outro enquanto semelhante ocupe este lugar. A consequência dessa operação consiste, em alguns momentos, no Outro enquanto invasor para o psicótico. Devemos ressaltar que o conceito de Outro em Lacan sofreu diversas modificações ao longo de sua obra.
} 
A dimensão clínica dentro da reabilitação nos aponta para essa categoria de inserção social que definimos, considerando as formas como cada sujeito realiza sua capacidade de laço social com o campo do Outro, campo esse que - esperamos - também se modifique a partir desse encontro. Na contramão do assistencialismo ou de outras tentativas de inclusão social, a inserção aponta para a construção do sujeito, exaltando o que é da ordem do singular. Por isso reconhecemos o papel de destaque da psicanálise, que está a serviço de uma escuta guiada por uma ética. É essa escuta que consideramos fundamental no trabalho do AT. Uma escuta presente na companhia, nas andanças pela cidade, na apropriação do paciente de seu espaço social.

\section{O início do acompanhamento terapêutico}

De acordo com Reis Neto (1995), a partir do contexto da reforma psiquiátrica, o AT surge na década de 1960 na Argentina, mais especificamente fazendo parte da equipe do Centro de Estudos e Tratamento de Abordagem Múltipla em Psiquiatria (CETAMP). Nessa instituição, conforme nos relata Hermann (2008), diante da dificuldade de aderência ao tratamento que alguns pacientes apresentavam, "pensou-se que alguém da equipe pudesse ir ao encontro do paciente, para tentar novas estratégias de instalação do dispositivo de tratamento, de modo a tentar trazer o paciente para o tratamento institucional" (p. 37). Essa posição dentro da equipe já evidencia a presença do AT como parte do tecido institucional, um mediador entre a equipe e o paciente.

Antes de ser denominado como acompanhante terapêutico, a pessoa que exercia a função de mediador entre paciente e equipe teve outros nomes, como "amigo qualificado" e posteriormente "auxiliar psiquiátrico". A mudança do nome foi importante para que o AT se consolidasse enquanto dispositivo, pois se o termo "auxiliar" indicava subordinação, a expressão "amigo qualificado" indicava algo da ordem do amistoso e de uma relação simétrica entre paciente e terapeuta (Santos, Motta, \& Dutra, 2005).

A virada que ocorre na denominação do AT se encontra no livro Acompanhamento terapêutico e pacientes psicóticos, de Susana Mauer e Silvia Resnizky (1987), autoras argentinas que apresentam sua experiência no CETAMP. Segundo as autoras, a mudança no 
nome diz respeito à "delimitação e ao alcance do papel" (Mauer \& Resnizky, 1987, p. 39), que vai se ampliando à medida que a experiência ocorre. Com a substituição de amigo qualificado para acompanhante terapêutico, "acentuou-se o que de terapêutico tinha este tipo de função assistencial" (Mauer \& Resnizky, 1987, p. 39). Ou seja, essa nova denominação traz o enfoque para o terapêutico, pensando-se além da função de assistência que é requerida.

No início dessa prática não era necessária nenhuma formação específica para exercer a função, que estava mais ligada aos cuidados físicos com os pacientes, atividades recreacionais, higiene etc. Porém, é interessante considerar o que nos apontam Santos, Motta e Dutra (2005) sobre a experiência do acompanhante terapêutico no CETAMP, que "figurava entre os outros profissionais, sem qualquer relação de subordinação. Neste sentido, era uma experiência que antecipava o que hoje chamamos de 'prática feita por muitos'” (p. 499).

Sobre o surgimento do AT no Brasil, Bazhuni (2010) indica que aqui em nosso país a prática teve início na clínica Pinel, em Porto Alegre, nos anos 1960. A autora destaca os trabalhos na Clínica Villa Pinheiros, no Rio de Janeiro, entre 1969 e 1976. Essa clínica tem uma particular importância dentro da evolução do AT no Brasil, haja vista que é lá que o então auxiliar psiquiátrico consegue sair da instituição e realizar o seu trabalho fora dela (Santos et al., 2005). Esse é um fator importante, pois conforme nos ressaltam Guerra e Milagres (2005), somente quando o acompanhante terapêutico sai para a rua com o paciente é que se amplia sua função e, consequentemente, é que se pode pensar numa clínica do AT.

Também devemos ressaltar o trabalho realizado pelos acompanhantes terapêuticos do Instituto A Casa, de São Paulo, que foi publicado em 1991 sob o título A rua como espaço clínico. Em Belo Horizonte, destacamos o trabalho efetivado pela clínica Urgentemente, que em 1998 ofereceu um curso de formação de acompanhantes terapêuticos com duração de dois anos (Santos et al., 2005).

O entrelaçamento do AT com a reforma psiquiátrica implica em considerarmos as especificidades do setting: agora se trata do espaço fora do manicômio, na cidade, no território, inserido na comunidade. Destacamos, então, o que Antônio Lancetti (2008) denomina como clínica peripatética, que diz respeito ao passear conversando, ou seja, à 
experiência clínica realizada fora do consultório, envolvendo ações dentro dos territórios. Aliás, o autor cita a experiência do AT enquanto pertencente à clínica peripatética, ressaltando a criação do primeiro concurso público na cidade de Santos para acompanhantes terapêuticos. Nessa perspectiva de Lancetti, salientamos como o AT se insere na rede de cuidados, de modo comunitário, para além da dimensão clínica que o dispositivo evoca. Conforme nos afirma Palombini (2006), o AT coloca em análise "o funcionamento da rede e as formas como as comunidades locais, a começar pelas famílias, respondem à desinstitucionalização da loucura" (p. 118).

O termo peripatético está relacionado à escola do filósofo Aristóteles, denominada Liceu. Aristóteles frequentava a Academia de Platão, seu mentor, e alguns anos após a morte de seu mestre funda o Liceu. Apesar de ter as influências do pensamento de Platão, Aristóteles apresentou diferenças marcantes em sua filosofia, haja vista que o Liceu, com proposta mais empírica, diferencia-se da Academia, focada no pensamento teórico. Cabe lembrarmos a famosa inscrição no portal da Academia de Platão, proibindo a entrada de quem não fosse geômetra 6 . Tal condição para os iniciados na Academia denota a importância que Platão dava ao estudo da Geometria e da Matemática, e aqui podemos diferenciar o ensino no Liceu aristotélico, que contava com um caráter mais empírico e prático. Podemos supor uma maior seleção do público para participar da Academia em relação ao Liceu, diante das diferenças apontadas.

A característica peripatética do Liceu diz respeito ao local e ao modo de ensino.

A escola filosófica fundada por Aristóteles (384-322 a. C.) tornou-se conhecida pelo nome de peripatética em virtude do costume do Estagirita ${ }^{7}$ de ensinar andando pelos jardins de Apolo no Liceu, perto de Ilissos, nas cercanias de Atenas. (Lancetti, 2008, p. 15 , grifo do autor)

O filósofo David Ross (n.d.) nos explica que Aristóteles passeava com seus alunos todas as manhãs e "discutia com eles questões mais obscuras da filosofia; depois, de tarde

\footnotetext{
6 Segundo o dicionário Michaelis (2015), geômetra é a "pessoa especializada em geometria”.

7 Segundo o dicionário Michaelis (2015), estagirita é "relativo ou pertencente a Estagira (Macedônia antiga), cidade onde nasceu o filósofo grego Aristóteles (384-322 a.C.)”.
} 
ou de noite, expunha as questões menos árduas a um público mais vasto ${ }^{\prime \prime}$ (p. 12, tradução nossa). Ross (n.d.) ressalta a distinção que é feita nos dois tipos de ensino de Aristóteles: os ensinamentos em forma de narrativas (a escola peripatética) e os ensinamentos exotéricos (transmitidos ao grande público), sendo que as matérias repassadas de forma peripatética eram mais abstratas (Lógica e Física, por exemplo), enquanto as matérias repassadas ao grande público diziam respeito às demandas mais gerais, como a retórica ou a política.

Interessante salientarmos duas características da escola peripatética de Aristóteles: se desenvolve em um ambiente aberto, do lado de fora, e concentra os ensinamentos mais abstratos, com estudos mais aprofundados. Podemos pensar numa lógica topológica para analisarmos essas características; uma lógica do dentro-fora, representada pelo cross-cap.

\section{Figura 1}

$$
\text { Cross-cap }
$$

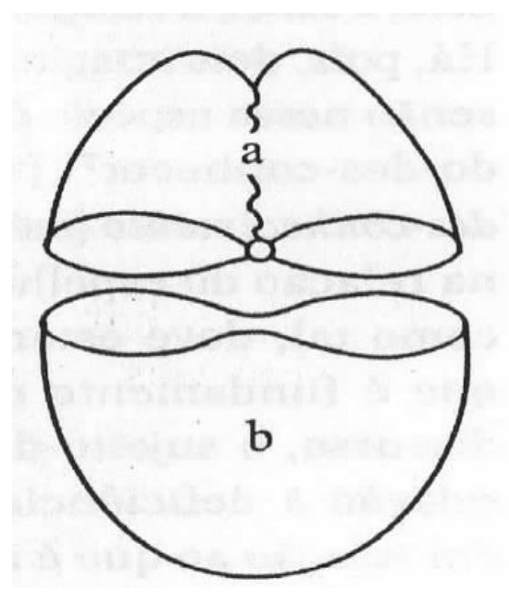

Fonte: Lacan (1961-1962/2003, p. 394).

Aqui temos uma subversão do espaço, que se caracteriza como um "dentro-fora" que se mistura, em continuidade. Através desse modelo asférico, que se contrapõe à esfera (marcada por um espaço interior e outro exterior), podemos compreender a escola peripatética como estando fora (nos jardins) e ao mesmo tempo dentro (profundidade do que se aprende). 8 "[...] discutía con ellos las cuestiones más abstrusas de la filosofía; después, por la tarde o por la noche, exponía las cuestiones menos
arduas a un público más vasto". 
Consideramos que essa lógica também se aplica ao AT, que se faz numa clínica peripatética. A aposta é justamente nesse dentro-fora: sair com o paciente em uma clínica ampliada e a céu aberto, observando sua singularidade e a maneira como se efetiva o laço social. Ao mesmo tempo em que o AT se desenvolve do lado de fora e com objetivos diversificados em relação a cada paciente (como por exemplo, ir ao banco sacar um dinheiro ou acompanhar uma consulta), a prática traz em si a profundidade de se deparar com a transferência na psicose e o manejo clínico diante de inúmeras contingências pelo caminho. Também é possível pensar no movimento que o AT poderá fazer sobre a instituição e o sujeito acompanhado, pois podemos dizer que a instituição possui uma aparência esférica (com dentro e fora bem demarcados), ao passo que com o AT há a possibilidade de fazer operar um modo asférico, articulando o fora-dentro.

Sobre a característica da clínica peripatética, Lancetti (2008) nos pontua que nunca se trata de adicionar nem de ocupar a pessoa com uma atividade, de dispor de uma ação como artefato. E à medida que a história se desenvolve, novos trechos de uma biografia vão sendo conhecidos, novos efeitos vão sendo gerados. (pp. 113114)

Essa pontuação nos remete à questão da própria característica do tratamento mental em meio aberto, em que insistem as variáveis não controláveis e o encontro com o contingente. O AT, pensado na disposição ética do seu fazer, deve estar sempre atento à história que desenvolve junto ao acompanhado, percebendo o que se apresenta de contingente e o que se faz com isso.

Também é pertinente pensarmos sobre o AT e sua função para além da lógica do controle social, evitando que o acompanhante terapêutico se reduza a uma figura pedagógica ou educativa. Esse cuidado vai ao encontro da problematização acerca da reabilitação psicossocial, quando esta responde à demanda de aprendizagem de habilidades e de reeducar o paciente para que se adeque ao espaço social em que se encontra inserido. Também há uma confluência com a questão levantada sobre a desinserção social, que controverte a inclusão social destinada a todos os pacientes. Ao AT não cabe uma posição pedagógica, sob o pretexto de incluir o paciente numa vida dita "normal". É certo que existirão momentos em que a demanda por uma ação educativa ou pedagógica poderá se 
apresentar, mas é preciso questionar sob qual necessidade essa demanda se apresenta. Isso implicará na transferência entre acompanhante e paciente, para que se saiba o momento em que esse tipo de demanda poderá ou não ser atendido.

Sendo assim, cabe elucidarmos os objetivos do AT de acordo com sua operatividade. Por exemplo, Bazhuni (2010) traz duas dimensões do objetivo do AT, que se caracteriza "tanto por sair à rua com o paciente quanto ter por objetivo promover sua reabilitação social, como denominam algumas correntes, quanto promover a estabilização do sujeito no laço social, como sugere a contribuição lacaniana" (p. 40). Por isso mesmo destacamos a importância da formação teórico-prática de quem se propõe a ser acompanhante terapêutico, observando a disposição ética para ocupar esse lugar.

Temos também importantes apontamentos feitos por Viganò (2010) em seu texto "A construção do caso clínico em saúde mental". O autor chama a atenção para a diferença entre o caso social e o caso clínico. Segundo o autor, "enquanto o caso social é conduzido pelos operadores, o caso clínico é resolvido pelo sujeito, que é o verdadeiro operador, desde que nós o coloquemos em condições de sê-lo" (Viganò, 2010, p. 42). Ou seja, trata-se da distinção entre inclusão social e inserção, bem como do enfoque na autonomia do próprio paciente e de seu saber. Apostamos que a prática do AT possa ser orientada a partir desse direcionamento. Novamente apontamos a incidência da orientação clínica na reabilitação psicossocial, evitando qualquer risco de apagamento do sujeito.

Diante da característica dos nossos sujeitos como operadores do caso, como pensar em um método para o AT? Um ponto importante salientado por Santos et al. (2005) é o cuidado com a questão da identificação, ao lembrar-nos que ela implica alienação: o papel do AT não é o de ser imitado, mas promover o sujeito como operador. As autoras ressaltam então o manejo da transferência como fundamental na relação entre acompanhante e acompanhado e afirmam que, amparado pela teoria lacaniana, o AT é pensado como "um dispositivo de regulação do gozo ${ }^{9}$ do sujeito e uma forma de apresentar um Outro não invasivo" (Santos et al., 2005, p. 507). Hermann (2008) considera fundamental no contexto

\footnotetext{
9 O gozo é um conceito lacaniano, que assim como o conceito do Outro, também sofreu modificações ao longo de sua obra. Freud já trazia algo do gozo quando dizia sobre os caminhos da formação dos sintomas e a modalidade de satisfação libidinal, mesmo no desprazer, na repetição, na dor. Portanto, o gozo está articulado à pulsão de morte e à repetição, algo que Lacan desenvolve em seu ensino. Para saber mais sobre o gozo na teoria lacaniana, recomendamos a leitura do texto "Os seis paradigmas do gozo", de J-A. Miller (2012).
} 
do AT o "olhar em rede", que está relacionado à apropriação do território institucional pelo acompanhante terapêutico, sendo ele mais um componente inserido na instituição. O acompanhante terapêutico seria então um articulador entre a instituição e o paciente, sendo esta uma estratégia de manejo da transferência.

Diante da caracterização do Acompanhamento Terapêutico, principalmente levando em conta sua função, que engloba o encontro com as surpresas na vida de cada paciente, seu encontro com a cidade, com a instituição, com a família, enfim: considerando esse encontro com o contingente, é importante situar essa característica na prática do AT.

\section{Prudência e contingência}

Já analisamos a mudança que ocorre no tratamento em saúde mental, que a partir da reforma psiquiátrica passa de um universo controlado dos hospitais para o tratamento em meio aberto, sujeito às contingências de variáveis não controláveis. Portanto, se agora estamos lidando com essa nova forma de tratamento, em que há o surgimento do Acompanhamento Terapêutico justamente pela especificidade do novo modo de tratar o paciente, como pensar no encontro com o contingente de maneira a nos nortear?

Para melhor nos situarmos nesse assunto, consideramos importante abordar a questão da prudência, que está diretamente relacionada ao que é da ordem do contingente, conforme estabelecido por Aristóteles (Teixeira, 2012). A distinção que Aristóteles faz entre ciência e prudência oferece uma melhor compreensão sobre a implicação da prudência com a contingência, conforme nos explica Teixeira (2012):

Diferentemente da ciência e da sabedoria, estruturados como saberes contemplativos daquilo que se apresenta enquanto necessário e imutável, o exercício da prudência diz respeito ao cálculo da ação referido ao dado contingente de uma realidade prática da qual fala Aristóteles no livro 6 de sua Ética a Nicômaco. (pp. 65-66)

Pierre Aubenque (2008), em seu livro $A$ prudência em Aristóteles, afirma que "a prudência é uma disposição prática que concerne à regra da escolha" (p. 61, grifo do autor). Essa regra da escolha diz respeito justamente ao domínio do fazer, em sua disposição prática, ou intenção. Mas o autor nos explica que essa definição poderia ser aplicada a 
qualquer virtude intelectual por ser muito ampla e, assim, distingue a prudência da sabedoria: o domínio da prudência seria o bem e o mal para o homem concreto situado em seu contexto particular, e não no contexto geral, que seria o domínio da sabedoria.

Além disso, Aubenque (2008) ressalta que Aristóteles não parte de uma essência da prudência, e sim de um nome. O nome phronimos (prudente) irá designar "um certo tipo de homem que todos sabemos reconhecer" (p. 62), e além disso, designa alguém que não opera com o transcendente, mas sim "move-se no nível do particular e fixa a cada um o justo meio que corresponde a sua particularidade" (p. 70).

Portanto, o que designa o homem prudente não se trata da sapiência, do saber prédeterminado ou da ordem do que é necessário (e paralelamente, científico); trata-se de um saber que é manifestado a partir da contingência.

Se lembrarmos que Lacan, no Seminário 20: Mais, ainda (1972-1973/1985b), utiliza as categorias modais extraídas de Aristóteles: possível, impossível, necessário e contingente ${ }^{10}$, podemos compreender que o necessário (correlato da ciência) aponta para o que se escreve sempre, enquanto a contingência (correlata da prudência) diz daquilo que às vezes se escreve. Por isso, justifica-se a dualidade aqui recorrida entre ciência e prudência, no contexto da mudança no tratamento mental explicitado anteriormente. Se antes o tratamento era controlado cientificamente intramuros, a partir da reforma esse tratamento se abre para o encontro com o não sabido, o não controlável do contingente.

Diante disso, ao questionarmos o método do AT, é pertinente apreendermos o conceito de prudência e sua relação com o contingente. Se anteriormente falamos de uma lógica do contingente a partir da reforma psiquiátrica e o novo modelo de tratamento mental, agora podemos concernir essa mesma lógica a serviço de um método que se constrói na colocação, em ato, entre o AT e seu paciente. Ou seja, pensar a contingência na perspectiva da clínica peripatética, que articula o dentro e o fora de maneira asférica, conforme explicitamos anteriormente.

\footnotetext{
10 Neste seminário, ao abordar a questão da linguagem e da escrita, Lacan (1972-1973/1985b) utiliza cada categoria modal da seguinte maneira: o possivel como o que cessa de se escrever (ao se escrever, cessa), o impossivel como o que não cessa de não se escrever (não se escreve), o necessário como o que não cessa de se escrever (se escreve sempre) e o contingente como o que cessa de não se escrever (às vezes se escreve).
} 
Temos um exemplo interessante, a respeito disso, de uma acompanhante terapêutica e o recurso que ela encontra no momento em que se depara com seu paciente. Essa experiência é relatada por Teixeira (2011):

[...] ao se ver diante de um psicótico grave, que residia numa habitação em ruínas em estado de quase mutismo, ela nota que a gaiola do canário era ali o único espaço relativamente bem cuidado. Ela consegue então romper o mutismo desse paciente, iniciando uma conversa sobre o pássaro que ele tão bem mantinha, não porque se interessasse por ornitologia, evidentemente. Mas isso não impede que o caminho que dá acesso ao paciente se configure no momento em que ela se coloca em movimento. (p. 5)

O saber que convoca a acompanhante terapêutica para uma conversa sobre o pássaro do paciente não está pré-determinado, e muito menos há um conhecimento prévio acerca da ornitologia: é a inventividade da acompanhante que se manifesta no momento desse encontro, diante de um dado contingente. Isso é algo que se apresenta na clínica do AT, quando quem está na posição de acompanhante terapêutico se vê convocado a observar o que o encontro com o contingente oferece enquanto suporte do laço social.

Teixeira (2012) nos convida a reabilitar o conceito de prudência na clínica psicanalítica, para dar conta do que é da ordem do contingente no sofrimento. Aliás, Miller (2011) nos afirma que

[...] a verdadeira psicanálise, no sentido de Lacan, é aquela que se põe no rastro do desejo e visa isolar, para cada um, sua diferença absoluta, a causa de seu desejo na sua singularidade, eventualmente a mais contingente. Disse eventualmente! A causa do desejo para cada um é sempre contingente. (p. 31 , grifo nosso)

Essa citação de Miller encontra-se em seu livro Perspectivas dos Escritos e Outros escritos de Lacan, em que o autor irá analisar a psicanálise do ponto de vista pragmático, a partir do furo entre a estrutura que organiza os conceitos fundamentais e a contingência. Nisso, Miller (2011) nos traz um apontamento importante a respeito do uso da palavra setting, que seria utilizada de maneira equivocada, visto que Lacan se refere ao discurso. "O setting é um conceito barroco que mistura ao mesmo tempo dados de estrutura e dados 
secundários, como instalação, número de encontros etc. Não se trata do setting, mas do discurso analítico" (Miller, 2011 , pp. 25-26).

Interessante notar que utilizamos a palavra setting ao caracterizar o espaço do AT: trata-se de um setting fora do consultório. Seria um ato falho? Sim, um ato falho marcado pela estrutura com a qual nos familiarizamos, marcada pelo atendimento dentro das paredes de um consultório. Portanto, devemos nos atentar ao que escapa na contingência, ao furo apontado por Miller, pois é com isso que o AT irá se haver.

\section{Considerações finais}

O Acompanhamento Terapêutico e seu importante papel para aqueles que necessitam desse dispositivo foi o tema que nos impulsionou neste trabalho. Percorremos a história da loucura para entender as posições que o louco ocupou ao longo do tempo, a partir da análise feita por Foucault (1978), e compreendemos como a reforma psiquiátrica foi imprescindível para a quebra do paradigma de tratamento excludente, para o qual os ideais antimanicomiais traçaram diferentes propostas de tratamento.

O AT, surgido no contexto da reforma psiquiátrica, traz consigo um lugar de fronteira, uma posição dentro-fora, entre o paciente, a instituição, a família, os amigos. Sua prática implica pensar o encontro com o contingente, pois o universo controlado dos hospitais cedeu espaço para o tratamento em meio aberto. O conceito da prudência nos ajudou a pensar nesse encontro, pois ela se relaciona com o saber manifestado a partir da contingência.

Quando concordamos com Palombini (2006) que a clínica do AT, por estar a serviço da desinstitucionalização, também envolve a desinstitucionalização da clínica mesma, ressaltamos a herança obtida da psiquiatria clássica, dos efeitos segregativos do tratamento fechado. Afirmamos que o AT traz a reflexão sobre a reforma psiquiátrica, não só por surgir a partir dela, mas também por apostar nessa clínica em movimento, a céu aberto.

Por isso, não podemos deixar de colocar os riscos constantemente sofridos pela política da reforma psiquiátrica e consequentemente pelo trabalho do AT quando analisamos os contextos políticos em que estamos inseridos e que estão em constante mutação. 
Acreditamos que o AT, orientado clinicamente pela psicanálise, não se furta de participar desse debate onde o seu próprio fazer se encontra ameaçado. Além da função clínica, apostamos também na função política do AT de reforçar sempre o cuidado em liberdade. Concluímos que este trabalho poderá suscitar posteriores pesquisas não só acerca da função clínica na prática do AT, como também de sua função política, de como sustentar um dispositivo que acolhe e acompanha o sujeito em meio aberto diante do mal-estar da exclusão e do silenciamento.

Nota: O presente artigo é fruto de uma parte da dissertação de mestrado, sob orientação do Prof. Dr. Antônio Márcio Ribeiro Teixeira - Mestrado em Programa de Pós-Graduação em Psicologia - Faculdade de Filosofia e Ciências Humanas, Universidade Federal de Minas Gerais.

\section{Referências}

Amarante, P. (Org.). (1995). Loucos pela vida: a trajetória da reforma psiquiátrica no Brasil. Rio de Janeiro: Fiocruz.

Aubenque, P. (2008). A prudência em Aristóteles (2a ed.). São Paulo: Discurso Editorial, Paulus.

Bazhuni, N. F. N. (2010). Acompanhamento Terapêutico como dispositivo psicanalítico de tratamento das psicoses na saúde mental [Dissertação de Mestrado, Universidade de São Paulo]. Biblioteca Digital de Teses e Dissertações da USP. https://doi.org/10.11606/D.47.2010.tde-30072010-111155

Equipe de acompanhantes terapêuticos do hospital-dia "A Casa" (Org.). (1991). A rua como espaço clínico: acompanhamento terapêutico. São Paulo: Escuta.

Estagirita. (2015). In Michaelis dicionário brasileiro da língua portuguesa. São Paulo: Editora Melhoramentos. http: / / michaelis.uol.com.br/busca? $r=0 \& f=0 \& t=0 \&$ palavra $=$ estagirita

Foucault, M. (1978). História da loucura na idade clássica. São Paulo: Perspectiva. 
Geômetra. (2015). In Michaelis dicionário brasileiro da língua portuguesa. São Paulo: Editora Melhoramentos. http://michaelis.uol.com.br/moderno-portugues/busca/portuguesbrasileiro/Ge\%C3\%B4metra/

Goffman, E. (1974). Manicômios, prisões e conventos. São Paulo: Perspectiva.

Guerra, A. M. C. (2004). Reabilitação psicossocial no campo da reforma psiquiátrica: uma reflexão sobre o controverso conceito e seus possíveis paradigmas. Revista Latinoamericana de Psicopatologia Fundamental, 7(2), 83-96. https:// doi.org/10.1590/1415-47142004002005

Guerra, A. M. C., \& Milagres, A. F. (2005). Com quantos paus se faz um acompanhamento terapêutico?: contribuições da psicanálise a essa clínica em construção. Estilos da Clínica, 10(19), 60-83. https://www.revistas.usp.br/estic/article/view/169976

Hermann, M. C. (2008). Acompanhamento Terapêutico e psicose: um articulador do real, simbólico e imaginário [Tese de Doutorado, Universidade de São Paulo]. Biblioteca Digital de Teses e Dissertações da USP. https://doi.org/10.11606/T.47.2008.tde$01122009-105523$

Koyré, A. (1991). Do mundo do "mais-ou-menos" ao universo da precisão. In A. Koyré, Estudos de história do pensamento filosófico (pp. 271-288). Rio de Janeiro: Forense Universitária. (Obra original publicada em 1947)

Lacan, J. (1985a). O Seminário, livro 3: As psicoses (A. Menezes, Trad.). Rio de Janeiro: Jorge Zahar. (Obra original publicada em 1955-1956)

Lacan, J. (1985b). O Seminário, livro 20: Mais, ainda (M. D. Magno, Trad.). Rio de Janeiro: Jorge Zahar. (Obra original publicada em 1972-1973)

Lacan, J. (2003). O seminário, livro 9: A identificação. (I. Corrêa, \& M. Bagno, Trads.). Recife: Centro de Estudos Freudianos do Recife. (Obra original publicada em 1961-1962)

Laia, S., \& Aguiar, A. A. (2017). Enigma, objetivação e diluição da loucura. In A. Teixeira, \& H. Caldas (Orgs.), Psicopatologia lacaniana l: semiologia (pp. 13-33). Belo Horizonte: Autêntica.

Lancetti, A. (2008). Clínica peripatética. São Paulo: Hucitec.

Mauer, S., \& Resnizky, S. (1987). Acompanhamento terapêutico e pacientes psicóticos: manual introdutório a uma estratégia clínica (W. P. Rosa, Trad.). Campinas: Papirus. 
Miller, J-A. (2011). Perspectivas dos Escritos e Outros escritos de Lacan. Rio de Janeiro: Jorge Zahar.

Miller, J-A. (2012). Os seis paradigmas do gozo. Opção Lacaniana, 3(7). http://opcaolacaniana.com.br/pdf/numero_7/Os_seis_paradigmas_do_gozo.pdf

Palombini, A. L. (2006). Acompanhamento terapêutico: dispositivo clínico-político. Psychê, 10(18), 115-127. http://pepsic.bvsalud.org/pdf/psyche/v10n18/v10n1 8a12.pdf

Pitta, A. (Org.). (2016). Reabilitação psicossocial no Brasil (4a ed.). São Paulo: Hucitec.

Reis Neto, R. O. (1995). Acompanhamento terapêutico: emergência e trajetória histórica de uma prática em Saúde Mental no Rio de Janeiro [Dissertação de Mestrado, Pontifícia Universidade Católica de Rio de Janeiro].

Ross, W. D. (n.d.). Aristóteles (2a ed., D. F. Pró, Trad.). Buenos Aires: Editora Charcas. https://drive.google.com/file/d/OB0_FjdluRK7uR1JJNVhzQ1 IScHFqbDA0ejg5emtuQQ/vie w

Santos, L. G., Motta, J. M., \& Dutra, M. C. B. (2005). Acompanhamento Terapêutico e clínica das psicoses. Revista Latinoamericana de psicopatologia Fundamental, 8(3), 497-514. https://doi.org/10.1590/1415-47142005003007

Saraceno, B. (2001). Libertando identidades: da reabilitação psicossocial à cidadania possível (2a ed.). Rio de Janeiro: Te Corá/Instituto Franco Basaglia.

Teixeira, A. (2010). Da inserção em saúde mental. Revista aSEPHallus, 6(11). http://www.isepol.com/asephallus/numero_1 1 /artigo_04_revistal 1.html

Teixeira, A. (2011). Singularidade subjetiva e metodologia clínica. CliniCAPS, 5(13), 1-7. http://www.clinicaps.com.br/clinicaps_pdf/Rev_13/Padronizado\%20Antonio\%20Teixeira .$p d f$

Teixeira, A. (2012). A prudência do psicanalista. In T. C. Santos, J. Santiago, \& A. Martello (Orgs.), De que real se trata na clínica psicanalítica? Psicanálise, ciência e discursos da ciência (pp. 63-80). Rio de Janeiro: Cia. de Freud.

Teixeira, A. (2016). Posfácio Neurose, psicose, perversão: a implicação do sujeito na nosologia freudiana. In S. Freud, Obras Incompletas (v. 5, M. R. S. Moraes, Trad., pp. 327-347). Belo Horizonte: Autêntica. 
Viganò, C. (2010). A construção do caso clínico em saúde mental. Revista Curinga, 13, 3948.

Recebido em: 26/7/2018

Aprovado em: 18/12/2018 